\title{
Sistemas de integração lavoura-pecuária e políticas de mudanças climáticas ${ }^{1}$
}

\author{
Marcos da Silva Fernandes ${ }^{2}$, Marcus Vinicius Alves Finco ${ }^{3}$
}

\begin{abstract}
Integrated crop-livestock

systems and climate change policies

The Brazilian scenario for the agricultural activity expansion has generated economic returns to the country, but with high environmental liability. Within this context, the National Plan on Climate Change and the National Program for a Low Carbon Agriculture (LCA) were launched. This study aimed to simulate scenarios of agricultural production in the North-Central region of the Mato Grosso State, Brazil. By using linear programming models, the potential of crop-livestock integration (CLI) systems was evaluated as a low carbon emission alternative to the traditional agricultural systems in the region. The results showed that CLI systems cannot be considered an attractive alternative to the farmers, since there are production strategies that generate higher economic gains. Likewise, the tools implemented by the LCA program were not enough for promoting the agricultural production in CLI systems. The study also aimed to evaluate the impact of the Certified Emission Reduction (CER) in areas planted under CLI systems. The results showed that the carbon credit system can be an important fomenting tool, in which, at the rate of $\$ 25.00$ per CER ( 1 ton of equivalent $\mathrm{CO}_{2}$ ), the producer could get expressive economic gains, due to the implementation of CLI systems.
\end{abstract}

KEY-WORDS: Agriforestal systems; linear programming; carbon credit.

\section{INTRODUÇÃO}

Ao longo de muitos anos, o Brasil vem se caracterizando como um dos grandes produtores agropecuários do mundo, sendo que, especialmente nas últimas duas décadas, este processo vem se intensificando, com um avanço significativo deste setor na economia. Este período coincide com a consolidação do Cerrado brasileiro como área de alta capacidade produtiva, onde parte expressiva

\section{RESUMO}

O cenário brasileiro de expansão da atividade agropecuária tem gerado retornos econômicos para o País, porém, com grande passivo ambiental. Dentro deste contexto, foram criados o Plano Nacional sobre Mudança do Clima e o Programa Nacional para uma Agricultura de Baixo Carbono (Programa ABC). Este trabalho objetivou simular cenários de produção agropecuária, na região Centro-Norte do Estado do Mato Grosso. Por meio de modelos de programação linear, avaliou-se o potencial de sistemas de integração lavoura-pecuária (ILP), como alternativa de baixa emissão de carbono aos sistemas tradicionais de cultivo da região. Os resultados obtidos apontaram que os sistemas de ILP não se apresentam como alternativa atraente para os produtores da região, existindo estratégias de produção que geram ganhos econômicos superiores. Da mesma forma, as ferramentas implantadas pelo Programa ABC não se mostraram suficientes para o fomento da produção agropecuária em sistemas de ILP. O estudo buscou avaliar, ainda, o impacto da implantação de Certificados de Redução de Emissões (CRE), na área plantada em sistemas de ILP. Os resultados indicaram que o sistema de crédito de carbono pode ser um importante instrumento de fomento, sendo que, ao valor de U\$ 25,00 por CRE ( 1 tonelada de $\mathrm{CO}_{2}$ equivalente), o produtor obteria ganhos econômicos expressivos, devido à implantação de sistemas de ILP.

PALAVRAS-CHAVE: Sistemas agroflorestais; programação linear; crédito de carbono.

do setor se distanciou das práticas extrativistas, as quais, por muitos anos, caracterizaram esta atividade (Townsend et al. 2009).

Dentro do processo descrito acima, o Estado do Mato Grosso possui papel central, sendo responsável, atualmente, por grande parte da produção agropecuária do País (Figueiredo et al. 2005). A partir da década de 1970, a fronteira agrícola do Estado modernizou-se e expandiu-se significativamente, com a criação de rodovias e políticas de incentivo

1. Trabalho recebido em ago./2013 e aceito para publicação em jun./2014 ( $n^{\circ}$ registro: PAT 26242).

2. Universidade Federal do Tocantins (UFT), Departamento de Ciências Econômicas, Palmas, TO, Brasil. E-mail: marcos_silfer@hotmail.com.

3. Universidade Federal do Tocantins (UFT), Departamento de Administração, Palmas, TO, Brasil.E-mail: marcus.finco@gmail.com. 
fiscal, acarretando a implantação de diversos projetos agroindustriais (Oliveira et al. 2005).

Ao mesmo tempo, a agenda política mundial foi revista e se direcionou, nas três últimas décadas, para questões ambientais, mais especificamente para os impactos gerados por atividades antrópicas ao meio ambiente e as consequências deste processo na sustentabilidade econômica, social e ambiental da população mundial. Dentro deste contexto, destaca-se a crescente preocupação em relação às mudanças do clima no planeta, principalmente as emissões de dióxido de carbono $\left(\mathrm{CO}_{2}\right)$ e outros gases causadores do efeito estufa (GEE), tais como o óxido nitroso $\left(\mathrm{N}_{2} \mathrm{O}\right)$ e o metano $\left(\mathrm{CH}_{4}\right)$ (IPCC 2007).

Porém, apesar da constatação da intensidade do problema das mudanças climáticas e da magnitude das mudanças do uso da terra, nesse processo, principalmente em países tropicais, os mecanismos internacionais que visam à mitigação das emissões de GEE, criados até o presente momento, têm, de alguma forma, negligenciado a problemática que envolve a mudança do uso da terra, não podendo esta modalidade ser abrangida, por exemplo, dentre aquelas capazes de gerar créditos de carbono, visando a financiar as reduções das emissões e, por consequência, o desenvolvimento regional sustentável.

Desse modo, a intensificação do uso da terra em áreas já desmatadas (áreas "abertas") surge como uma das alternativas aceitas pelos diferentes agentes envolvidos no processo de desenvolvimento sustentável da agropecuária. A criação de técnicas para restabelecer a capacidade produtiva de áreas degradadas destinadas à pastagem e à produção de grãos, por exemplo, é fundamental para alcançar a sustentabilidade e aumentar a eficiência agropecuária dos Cerrados (Vilela et al. 2008). Assim, a integração dos sistemas de produção de grãos e pecuária desponta como uma das opções viáveis.

Sistemas de integração lavoura-pecuária (ILP) são definidos como sistemas mistos de exploração de culturas agrícolas e pecuárias, caracterizados pela diversificação, rotação, consorciação e/ou sucessão de atividades de agricultura e pecuária (Kluthcouski et al. 1991). Entre as principais vantagens destes sistemas reside o fato de o solo ser utilizado economicamente durante todo o período anual, ou, pelo menos, na maior parte dele, favorecendo o aumento na oferta de grãos, carne e leite a um custo menor, devido, principalmente, à sinergia criada entre a lavoura e a pastagem (Gonçalves \& Franchini 2007).
Porém, os ganhos de produtividade gerados estão intimamente ligados a ganhos ambientais decorrentes de sua implantação.

Com base nos benefícios ambientais gerados pela ILP, este sistema de produção agropecuário foi inserido, em 2010, no Programa de Agricultura de Baixo Carbono (ABC), gerenciado pelo Ministério da Agricultura, Pecuária e Abastecimento (MAPA). Além do Programa ABC, a ILP está inserida dentro das possibilidades de mitigação de gases do efeito estufa (GEE), como uma das ferramentas prioritárias do Plano Nacional sobre Mudança do Clima (PNMC).

Diante do exposto, este estudo objetivou avaliar, por meio de modelos de programação linear, a capacidade de os sistemas de ILP se tornarem uma alternativa ao sistema tradicional de cultivo dos solos, na região Centro-Norte do Estado do Mato Grosso. Objetivou-se avaliar, por exemplo, se a estratégia adotada pelo Programa ABC, constituída pela concessão de crédito com taxas de juros reduzidas, é suficiente para o fomento das atividades de ILP. Da mesma forma, o trabalho procura avaliar os impactos oriundos de um cenário onde créditos de carbono são atrelados às mudanças no uso da terra, como ferramenta de fomento e implantação de sistemas de ILP.

\section{MATERIAL E MÉTODOS}

Um modelo de programação linear multiperíodo foi aplicado dentro de diversos cenários estabelecidos, visando a estimar a otimização dos ganhos do produtor, na região Centro-Norte do Estado do Mato Grosso, tendo como base as safras de 2011 e 2012. A função objetivo deste modelo é maximizar os ganhos do produtor agropecuário, dentro dos diferentes cenários. Para tanto, um modelo básico foi aplicado, ex ante, buscando obter os resultados dentro do atual contexto de produção, na região de estudo. Em seguida, foram simulados os diferentes cenários, sendo que o impacto destes na produção foi determinado pela comparação entre o modelo básico e os modelos que contemplam os cenários propostos.

A modelagem foi aplicada, sobretudo, a fim de testar o impacto de diferentes situações de produção. Com base nisto, a concepção do modelo pôde ser apresentada em cinco passos: 1) construção do modelo básico para descrever o cenário padrão de produção; 2) validação do modelo; 3 ) calibração do modelo; 4) aplicação dos diferentes cenários de produção; 5) comparação do modelo básico com o 
resultado dos modelos com cenários (Finco \& Bauer 2010). A diferença entre eles permitiu descrever o impacto dos vários cenários.

O Instituto Matogrossense de Economia Agropecuária (IMEA) subdivide o Estado do Mato Grosso em sete macrorregiões (Figura 1). Esta divisão é realizada de acordo com características específicas, como bioma, bacias hidrográficas, clima, condições do solo, topografia e altitude.

O trabalho focou os esforços de pesquisa para a região denominada Centro-Norte, que está localizada na área de transição entre os biomas Cerrado e Amazônico, apresentando características de solo, topografia e clima adequadas à produção de culturas anuais, como a soja e o milho.

Até o ano de 2000, o crescimento da economia da macrorregião Centro-Norte decorreu, principalmente, da abertura de extensas faixas de terra ao cultivo agrícola, tendo o desenvolvimento tecnológico como fator menos importante. Porém, nos últimos anos, este contexto tem se alterado, em consequência, principalmente, do aumento da preocupação global, quanto à abertura de áreas de floresta para cultivo. Este fato fez com que a taxa de desmatamento para fins agrícolas, da região, diminuísse consideravelmente, porém, com aumento constante da produção agrícola, fruto do intenso processo de modernização dos sistemas produtivos, na região (IMEA 2010).

Responsável por grande parcela da produção agrícola do Estado, a macrorregião Centro-Norte do Mato Grosso merece destaque, tendo-se em vista que colabora, significativamente, para o incremento do PIB do Estado, principalmente em decorrência do alto nível de produção de grãos, como o milho e a soja.

O principal produto agrícola da região Centro-Norte do Mato Grosso é a soja, que corresponde a $65 \%$ da produção, em termos de volume, sendo responsável por $32 \%$ da produção de todo o Estado e $10 \%$ da produção nacional. Na região, destacam-se os municípios de Nova Ubiratã, Brasnorte, Ipiranga do Norte e, sobretudo, Sorriso, que é considerado o maior produtor nacional de soja, sendo responsável por mais de $10 \%$ do volume total do Estado do Mato Grosso e cerca de 3\% do total nacional (IBGE 2006).

O milho é o segundo produto agrícola, em volume de produção, na região Centro-Norte do Mato Grosso, correspondendo a $28 \%$ da produção agrícola. A produção total de milho da região Centro-Norte é de 2.393.715 toneladas, representando mais de 13\% da produção do Estado (IBGE 2006).

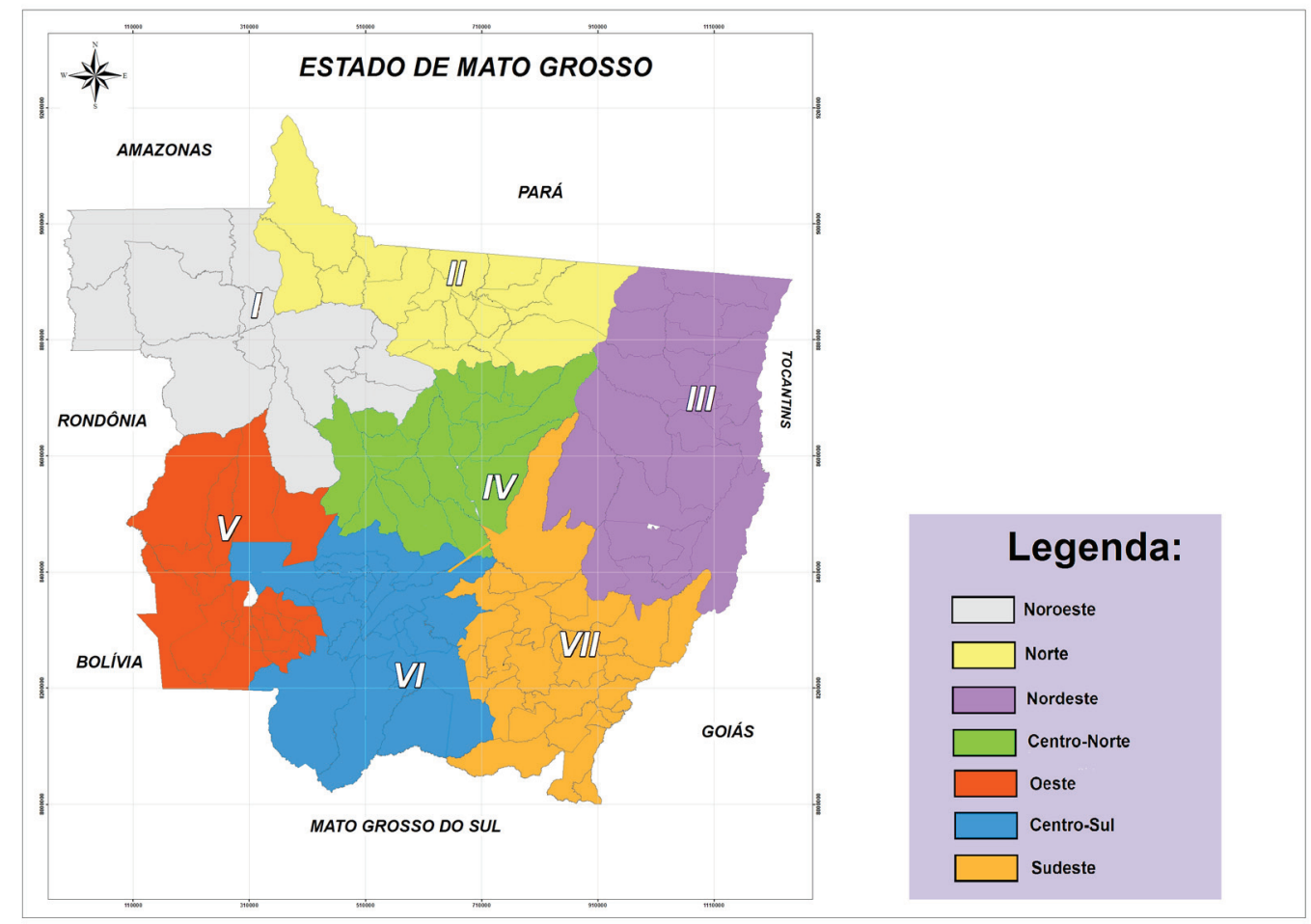

Figura 1. Macrorregiões do Estado do Mato Grosso. Fonte: IMEA (2010). 
O cultivo de milho, na região, é realizado em duas safras, porém, na primeira safra, o milho perde espaço para a soja, sendo a maior parte dele cultivado na segunda safra.

Além da soja e do milho, pode-se destacar, também, a importância das lavouras de arroz e algodão, na região, que, apesar de possuírem área plantada e volume de produção menores que a soja e o milho, são de grande importância econômica, tendo-se em vista que possuem valor de comercialização superior. Sendo assim, apesar de o volume da produção de algodão corresponder a apenas $4,3 \%$ do volume de milho produzido na região, o valor bruto gerado por esta cultura representa mais de $34 \%$ do valor da produção de milho (IMEA 2010).

Em um problema de Programação Linear (PL), a função de decisão linear deverá ser otimizada, bem como as constantes lineares satisfeitas, ambas simultaneamente. Neste processo, estão envolvidos diversos elementos, como as variáveis de decisão, que representam as decisões desconhecidas que devem ser tomadas; a função objetivo; e a expressão matemática que combina as variáveis, que deverá ser maximizada para se obter o resultado da função (Hazell \& Norton 1986).

O período de análise foi de 4 anos, visando-se a estabelecer um prazo mínimo para que fossem captados os benefícios advindos da utilização de sistemas de ILP, sendo importante destacar que a maior parte dos estabelecimentos agropecuários da região divide a produção em duas safras, a primeira cultivada no verão e a segunda no inverno (Machado et al. 2011). Desta forma, a margem bruta anual, calculada pela função objetivo, representou a soma dos rendimentos obtidos nas duas safras.

Este trabalho objetivou avaliar o cenário responsável pela maximização do rendimento do produtor agrícola. Deste modo, a função objetivo utilizada foi a maximização da margem bruta, que é calculada por meio da soma das receitas advindas das atividades, deduzidos os custos variáveis do produtor agrícola.

A estrutura matemática da função objetivo pode ser expressa pela seguinte equação:

$$
\operatorname{Max} Z=\sum_{j=1}^{n} P_{j} X_{j}-C_{j} X_{j}
$$

onde $Z$ representa a margem bruta total do produtor, $P_{j}$ o preço unitário da atividade $j, X_{j}$ a área ocupada pela atividade $j, C_{j}$ o custo unitário da atividade $j$ e $n$ o número de atividades.

Portanto, os componentes da função objetivo foram os seguintes: 1) custo variável para cada um dos cultivos agrícolas, para a produção pecuária, assim como para os sistemas integrados de cultivo, excluindo-se o custo dos salários dos trabalhadores; 2) preço médio de venda dos produtos agrícolas e pecuários, durante o período de safra dos cultivos; 3) custo da mão de obra utilizada pela atividade agropecuária, determinado pelo salário médio por pessoa, na região de estudo.

A limitação de recursos é uma característica intrínseca dos sistemas de produção agropecuária. Com base nisto, as restrições do modelo básico de programação linear representaram as limitações de recursos, em uma fazenda média da região de estudo. Desta forma, os agricultores devem atingir os seus objetivos, no caso da maximização dos seus rendimentos, por meio da utilização dos seus recursos limitados. Portanto, as diferentes opções de produção e de atividades agrícolas e pecuárias contribuem com a maximização da função objetivo, utilizando estes recursos limitados. Desta forma, a função objetivo explicitada anteriormente estará sujeita à seguinte condição:

$$
\begin{aligned}
& \sum_{j=1}^{n} a_{i j} X_{j} \leq b_{i} \text { para todo } i \text { de } 1 \text { até } m ; \\
& X_{j} \geq 0 \text { para todo } j \text { da } 1 \text { até } n
\end{aligned}
$$

sendo $X_{j}$ a área ocupada pela atividade $j, n$ o número de atividades, $a_{i j}$ a quantidade de recurso $i$ necessário para produzir uma unidade da atividade $j, m$ o número de recursos e restrições e $b_{i}$ a quantidade disponível do recurso $i$.

Foram adotadas as seguintes restrições:

Área do estabelecimento agropecuário: definida de acordo com as características dos estabelecimentos agropecuários da macrorregião Centro-Norte do Estado do Mato Grosso. Desta forma, no modelo, foi definido que a área total do estabelecimento era de 10.000 ha;

Reserva legal: a área cultivável do estabelecimento agropecuário é limitada pelo Código Florestal Brasileiro. Para a região de estudo, os estabelecimentos devem manter uma reserva legal mínima de 30\%;

Trabalhadores disponíveis: foi definido número máximo de 500 trabalhadores por safra, sendo este 
número determinado a partir do Censo Agropecuário do IBGE (2006). As informações referentes ao número de trabalhadores necessários para a produção de um hectare de cada atividade foram deduzidas, também, do Censo Agropecuário (2006), a partir da razão entre o número de trabalhadores total em cada atividade e a área plantada;

Crédito: A restrição referente ao crédito baseou-se nos limites financiáveis disponibilizados pelas diversas modalidades de crédito rural, sendo que, para a produção em sistemas convencionais de cultivo, o limite adotado foi de $\mathrm{R} \$ 650$ mil por safra e, para a produção em sistemas de ILP, o limite foi de R\$ 1 milhão por safra.

As atividades do estabelecimento agropecuário englobaram a produção agrícola, pecuária e sistemas de integração lavoura-pecuária, todas elas incluindo a atividade de venda dos seus produtos, além de atividades de uso da terra, contratação de trabalhadores e outras atividades não agrícolas. Desta forma, foram incluídas as seguintes atividades no modelo:

Produção agrícola: foram inseridas as atividades agrícolas que representam a maior parte da produção da região. Durante a safra, o agricultor tem a possibilidade de cultivar soja, arroz e milho. Já na safrinha, o produtor pode produzir soja, milho e algodão (IMEA 2012);

Produção pecuária: a atividade inserida no modelo foi constituída pela cria e engorda bovina para corte (IMEA 2012);

Produção em sistemas integrados: foram inseridas duas diferentes atividades de integração lavoura-pecuária. A primeira foi o cultivo de milho consorciado com forrageiras do gênero Brachiaria. A segunda foi a rotação entre lavoura e pecuária, com a área utilizada para cultivo agrícola em um ano e para pastejo no ano seguinte (Kitchel et al. 2009);

Crédito: a taxa de juros adotada baseou-se naquela aplicada pelo sistema convencional de crédito rural (6,75\% a.a.) e na aplicada para a produção em sistemas de baixa emissão de carbono (5,0\% a.a.);

Vendas: esta atividade foi inserida no modelo com os preços de venda referentes ao período de safra de cada produto, no ano de 2011, para as atividades de verão, e 2011/2012, para as atividades de inverno (IMEA 2012).

O primeiro modelo elaborado, denominado modelo básico, buscou refletir o atual cenário produtivo da região Centro-Norte do Estado do Mato Grosso, tentando se aproximar, ao máximo, das características da produção agropecuária da região. Para tanto, as variáveis e restrições foram inseridas seguindo-se os parâmetros médios da área de estudo, para a safra 2012/2013, a partir de dados obtidos tanto em fontes oficiais, como na literatura existente sobre o tema. A partir deste modelo, foram estipulados cenários para a comparação com o modelo básico.

O cenário aplicado consistiu na implantação de uma política que remunerasse os agricultores pela implantação de sistemas de ILP, considerando-se os benefícios ambientais por eles gerados. No presente caso, uma política de Certificados de Redução de Emissões (CRE) foi considerada, visando ao fornecimento de créditos de carbono, em decorrência da redução de emissões geradas pela implantação da ILP.

Este cenário teve como base o modelo básico. Contudo, foi incorporada ao modelo a possibilidade de o produtor gerar créditos de carbono, caso adotasse um sistema de produção agrícola de baixo carbono, sendo, no presente caso, considerados os sistemas de ILP. Os níveis de redução de emissões gerados pelos sistemas de ILP foram baseados em estimativas realizadas por Carvalho (2009).

Atualmente, os Certificados de Redução de Emissões são negociados no mercado financeiro e estão sujeitos a uma grande variação de preços, decorrentes da origem da redução de emissões e da quantidade de CRE disponíveis para venda, dentre outros fatores. Deste modo, foram simulados três cenários de preços de crédito de carbono, sendo eles U\$ 2,00, U\$ 15,00 e U\$ $25,00^{1}$ por tonelada de $\mathrm{CO}_{2}$ equivalente não emitido.

\section{RESULTADOS E DISCUSSÃO}

Os resultados obtidos pelo modelo básico estão apresentados na Tabela 1, na qual estão expostas todas as atividades agropecuárias inseridas no modelo, juntamente com as respectivas áreas de cultivo que constituem a estratégia que maximiza a margem bruta do produtor, para cada ano.

Como pode ser observado, durante a primeira safra, para todos os anos, o produtor optaria pelo uso de toda a área, para o cultivo da soja. Já durante a "safrinha", seria adotado o cultivo de milho em, aproximadamente, $44 \%$ da área agricultável, sendo que o restante permaneceria em pousio. Na região em questão, é comum a manutenção de parte da área

\footnotetext{
${ }^{1}$ Estes valores foram estipulados de acordo com o preço de comercialização de CRE na European Climate Exchange (ECX), que, no ano de 2012, variaram entre $\mathrm{U} \$ 0,80$ e U\$ 37,00 por tonelada de $\mathrm{CO}_{2}$ equivalente.
} 
Tabela 1. Área ocupada por cultivo de acordo com o modelo básico.

\begin{tabular}{clrrrr}
\hline \multicolumn{1}{c}{ Cultura } & Ano 1 & Ano 2 & Ano 3 & Ano 4 \\
\hline \multirow{5}{*}{ Safra } & Soja (ha) & 7.000 & 7.000 & 7.000 & 7.000 \\
\multirow{5}{*}{$1^{\text {a }}$ safra } & Milho safra (ha) & 0 & 0 & 0 & 0 \\
& Arroz (ha) & 0 & 0 & 0 & 0 \\
& Pastagem de verão (ha) & 0 & 0 & 0 & 0 \\
& Rotação lavoura-pastagem (ha) & 0 & 0 & 0 & 0 \\
& Milho + Brachiaria (ha) & 0 & 0 & 3.125 & 3.125 \\
$2^{\text {a }}$ safra & Milho safrinha (ha) & 3.125 & 3.125 & 0 & 0 \\
& Algodão (ha) & 0 & 0 & 0 & 0 \\
& Pastagem de inverno (ha) & 0 & 0 & 0 & 0 \\
& Milho + Brachiaria (ha) & 0 & 0 & 0 & 0 \\
& Rotação lavoura-pastagem (ha) & 0 & 0 & & 0 \\
\hline
\end{tabular}

Fonte: Resultados da pesquisa (2013).

em pousio, durante o inverno. Tal fato decorre dos riscos deste tipo de cultivo, em virtude de variações no preço de comercialização, bem como ao fato de o milho ser uma cultura de verão.

Os resultados obtidos com o modelo básico demonstraram que, no atual cenário produtivo da região Centro-Norte, os sistemas de ILP não conseguem competir, economicamente, com o cultivo tradicional de soja e milho, tendo-se em vista que estes ocupam toda a área produtiva.

O Plano ABC foi instituído visando a fomentar a produção agropecuária sustentável no País. Este plano está subdividido em sete diferentes programas, sendo seis deles destinados às tecnologias de produção agrícola sustentável e um último para projetos de adaptação às mudanças climáticas.

Nesse contexto, os resultados obtidos pelo modelo básico demonstraram que, na região em questão (Cento-Norte do MT), as ferramentas adotadas pelo Plano ABC são insuficientes para o fomento da produção em sistemas integrados. Mesmo obtendo-se crédito a juros menores e possuindo maior quantidade de recursos para financiamento de sua produção, seria mais vantajoso para o produtor continuar cultivando soja e milho no sistema tradicional de cultivo baseado na monocultura extensiva. Desta forma, os resultados aqui apresentados evidenciam que, apesar dos esforços para que os agricultores produzam em sistemas mais sustentáveis, seriam necessárias estratégias de fomento mais incisivas, para que os produtores da região Centro-Norte do Estado do Mato Grosso abandonassem seu atual sistema de cultivo.

A produção agropecuária, no Brasil, é constituída por uma grande variedade de culturas e atividades pecuárias, além dos diferentes sistemas produtivos. Esta diversificação decorre das diferenças regionais do País, apresentando características físicas e geográficas diversas, ao longo do seu território. Buscando abranger estas diferenças, uma das principais estratégias do MAPA, na adoção do Plano ABC, é o envolvimento dos Estados, por meio da integração da Política Nacional de Mudança Climática com os planos estaduais de redução das emissões por meio de Grupos Gestores Estaduais (GGE), acreditando que os gestores estaduais possuem maior conhecimento das especificidades da produção agropecuária local. A criação dos GGE foi efetivada, sendo que, até o início de 2013, estes foram implantados em 25 Estados.

Apesar da adesão dos Estados aos GGE, este processo tem se refletido de maneira tímida nas políticas nacionais relativas à redução das emissões de GEE. No caso particular do Plano ABC, atualmente, não são consideradas as especificidades regionais, sendo que esta política é caracterizada, basicamente, pelo fornecimento de recursos aos produtores via crédito rural, sem qualquer distinção referente à localidade do estabelecimento agropecuário. Com base neste contexto, a macrorregião Centro-Norte do Mato Grosso possui peculiaridades produtivas que inviabilizam a adoção de sistemas integrados de cultivo. Primeiramente, devido à excelência produtiva de grãos na região, torna-se necessária a implantação de fortes incentivos, para que o produtor altere a sua estratégia produtiva. Desta forma, como evidenciado pelo modelo aplicado no trabalho, para que os sistemas de ILP se tornem viáveis, em uma região que tem como base produtiva a monocultura extensiva, tornam-se necessárias 
Tabela 2. Área ocupada por cultivo de acordo com os cenários envolvendo Certificados de Redução de Emissões (CRE).

\begin{tabular}{|c|c|c|c|c|c|}
\hline \multirow{2}{*}{ Safra } & \multirow{2}{*}{ Cultura } & \multirow{2}{*}{ Modelo básico } & \multicolumn{3}{|c|}{ Cenário com CRE } \\
\hline & & & Cenário 1a & Cenário $1 \mathrm{~b}$ & Cenário 1c \\
\hline \multirow{6}{*}{$1^{\mathrm{a}}$ safra } & Soja (ha) & 7.000 & 7.000 & 7.000 & 2.643 \\
\hline & Milho safra (ha) & 0 & 0 & 0 & 0 \\
\hline & Arroz (ha) & 0 & 0 & 0 & 0 \\
\hline & Pastagem de verão (ha) & 0 & 0 & 0 & 0 \\
\hline & Rotação lavoura-pastagem (ha) & 0 & 0 & 0 & 0 \\
\hline & Milho + Brachiaria $($ ha) & 0 & 0 & 0 & 2.767 \\
\hline \multirow{5}{*}{$2^{\mathrm{a}}$ safra } & Milho safrinha (ha) & 3.125 & 3.125 & 3.125 & 660 \\
\hline & Algodão (ha) & 0 & 0 & 0 & 0 \\
\hline & Pastagem de inverno (ha) & 0 & 0 & 0 & 0 \\
\hline & Milho + Brachiaria (ILP) (ha) & 0 & 0 & 0 & 2.767 \\
\hline & Rotação lavoura-pastagem (ILP) (ha) & 0 & 0 & 0 & 0 \\
\hline
\end{tabular}

Fonte: Resultados do trabalho (2013). Cenário 1a: CRE ao preço de U\$ 2,00 $\mathrm{t}^{-1}$ de $\mathrm{CO}_{2}$ equivalente; Cenário $1 \mathrm{~b}$ : $\mathrm{CRE}$ ao preço de U\$ $15,00 \mathrm{t}^{-1}$ de $\mathrm{CO}$, equivalente; Cenário 1c: CRE ao preço de U\$ $25,00 \mathrm{t}^{-1}$ de $\mathrm{CO}_{2}$ equivalente.

políticas mais contundentes, para o fomento destes sistemas ${ }^{2}$.

Os resultados obtidos pelo modelo básico apresentaram a incapacidade de os sistemas de integração lavoura-pecuária competirem, economicamente, com os sistemas tradicionais de cultivo, na atual situação de produção da região Centro-Norte do Mato Grosso. Desta forma, para que o produtor opte por utilizar estes sistemas, seriam necessárias mudanças no atual panorama produtivo, que permitissem obter maiores ganhos econômicos com os sistemas de ILP.

Os resultados da modelagem de cenários são apresentados na Tabela 2. Este cenário tem como base o modelo básico já apresentado, possuindo parâmetros de produção iguais aos utilizados naquele modelo. Porém, foram acrescentadas atividades e restrições, objetivando captar a redução das emissões de gases de efeito estufa e a comercialização de créditos de carbono.

Pelos resultados obtidos, foi possível avaliar que, nos Cenários 1a e 1b, a situação do produtor se manteve inalterada, sendo cultivada soja durante a $1^{\text {a }}$ safra, ocupando toda a área agricultável da fazenda, e na $2^{\mathrm{a}}$ safra, quando parte da área foi utilizada para o cultivo do milho "safrinha". A partir destes resultados, pôde-se concluir que os preços de CRE a U\$2,00 e U\$ 15,00 por tonelada de $\mathrm{CO}_{2}$ equivalente não são

\footnotetext{
${ }^{2}$ A adoção de sistemas de produção mais sustentáveis passa, necessariamente, pela viabilidade desta mudança, para os agricultores. Apesar do recente crescimento da preocupação ambiental, caracterizado pelo aumento da pressão política e social, para que se reduzam os níveis de degradação, ao final do processo, o produtor agrícola acabará por cultivar os produtos que lhe proporcionarão maiores retornos econômicos. Sendo assim, torna-se imprescindível, para que o Plano ABC atinja os seus objetivos, no que se refere à expansão da área cultivada em sistemas de ILP, que se criem ferramentas que proporcionem ao produtor a possibilidade de reduzir os níveis de degradação, sem que seus ganhos sejam prejudicados.
}

suficientes para incentivar o produtor a cultivar suas áreas na totalidade, utilizando os sistemas integrados.

Já no Cenário $1 \mathrm{c}$, com os CRE sendo negociados no mercado ao preço de U\$25,00, o produtor passa a destinar grande parte de sua área para a produção em sistema de integração lavoura-pecuária. Observou-se que, durante a $1^{\mathrm{a}}$ safra, o produtor ocuparia mais da metade de sua terra com sistemas de ILP. Já na $2^{\mathrm{a}}$ safra, quando, novamente, foi ocupada apenas uma parcela da área agricultável, o produtor destinaria mais de $75 \%$ da sua área de lavoura para o cultivo em sistema de ILP.

De acordo com o resultado obtido, a estratégia ótima para o produtor seria utilizar o sistema de cultivo de milho consorciado com forrageiras do gênero Brachiaria. Este resultado é representativo, pois o preço de U\$ 25,00 por CRE é factível, tendo-se em vista que, durante o ano de 2012, as negociações no European Climate Exchange (ECX) chegaram a atingir preços de U\$ 37,00. Desta forma, os resultados apresentados indicam que o sistema de crédito de carbono pode ser uma ferramenta importante no fomento do cultivo em sistemas integrados, porém, sua efetividade dependeria dos valores de negociação do CRE.

Diversos estudos avaliaram a competitividade dos sistemas de ILP com os sistemas convencionais de cultivo, sendo que a maior parte deles conclui que a ILP é um sistema de produção economicamente viável, para o produtor. Porém, quando comparado o ganho econômico destes sistemas com o cultivo de lavouras solteiras, costumeiramente, os sistemas de ILP perdem competitividade. Ao testar a competitividade dos sistemas integrados de cultivo com a 
Tabela 3. Resultados econômicos e ambientais dos cenários simulados.

\begin{tabular}{lrrrr}
\hline Parâmetro & Modelo básico & Cenário 1a & Cenário 1b & Cenário 1c \\
\hline Área cultivada 1 $1^{\mathrm{a}}$ safra (ha) & 7.000 & 7.000 & 7.000 & 7.000 \\
Área cultivada 2 $^{\mathrm{a}}$ safra (ha) & 3.125 & 3.125 & 3.125 & 3.427 \\
Margem bruta total (R\$) & 5.321 .933 & 5.321 .933 & 5.321 .933 & 5.416 .213 \\
Mão de obra (trabalhadores) & 480 & 480 & 480 & 497 \\
Área destinada à ILP (ha) & 0 & 0 & 0 & 2.767 \\
Redução das emissões de $\mathrm{CO}_{2}(\mathrm{t})$ & 0 & 0 & 0 & $3.458,6$ \\
\hline
\end{tabular}

Fonte: Resultados do trabalho (2013).

produção solteira de soja e com a atividade pecuária, Martha Júnior et al. (2011) concluem que "a integração lavoura-pecuária compete com sistemas especializados de pecuária, mas não apresenta taxas de retorno competitivas, em comparação a sistemas especializados de cultivo". Apesar disto, os sistemas de ILP despontam como uma das principais alternativas para uma produção de baixa emissão de carbono, que permita a expansão da produção agropecuária e seja capaz de gerar ganhos econômicos para o produtor. Porém, como estes sistemas de produção não são competitivos, em relação aos sistemas tradicionais de cultivo, é necessário, caso se objetive expandir a produção nestes sistemas, que sejam fomentados, para que o produtor possa utilizá-los.

Um maior detalhamento dos resultados pode ser observado na Tabela 3, onde estão apresentados os lucros do produtor, mão de obra utilizada, área cultivada em cada safra, área destinada a sistemas de ILP e redução da emissão de GEE.

A partir dos resultados, é possível observar que não houve alterações, em relação ao modelo básico, para os Cenários 1a e 1b. No Cenário 1c, houve aumento na área utilizada em sistema de ILP, como apresentado anteriormente. A alteração de estratégia elevou a margem bruta ( $\mathrm{R} \$ 5.416 .213)$, representando aumento de R $\$ 94.280$ ao ano, em relação ao modelo básico. Por último, o Cenário 1c geraria redução de $3.458,6$ t de $\mathrm{CO}_{2}$ equivalente na emissão, a cada ano. Com a comercialização dos CRE, o produtor obteria rendimento superior a $\mathrm{R} \$ 173 \mathrm{mil}$, a cada ano, representando 3,2\% da margem bruta anual do produtor.

Outra análise importante a se fazer diz respeito aos riscos envolvidos na produção. $\mathrm{O}$ trabalho não objetivou avaliar este fator nos sistemas de cultivo, tampouco incorporou os riscos ao modelo. Porém, baseando-se em trabalhos existentes, é possível avaliar alguns fatores. A literatura que aborda a análise de risco em sistemas integrados de cultivo é pacífica, no que tange à capacidade de estes sistemas minimizarem o risco da produção agropecuária. Este fato decorre, principalmente, da diversificação de produtos e, em terras destinadas à agricultura, da inserção da criação bovina, que possui riscos menores do que as lavouras.

Os produtores rurais desenvolvem a sua atividade em ambiente dinâmico e incerto, em que variáveis econômicas e físicas encontram-se em constante mudança (Dent et al. 1986). Conforme a percepção de risco no negócio, os produtores rurais podem optar por atividades de menor risco, mesmo que isto implique em comprometimento dos lucros do produtor. A ILP pode atuar na redução dos riscos do negócio, pela diversificação das atividades agropecuárias na propriedade rural. Além deste efeito da diversificação, a rotação de culturas na propriedade rural pode contribuir, positivamente, para a redução de risco, pela menor variabilidade da produtividade entre os anos e pelo aumento na produtividade ou redução nos custos unitários de produção (Helmers et al. 2001).

Dessa forma, os resultados apresentados pelo Cenário 1c se tornam mais consistentes, tendo-se em vista que o produtor teve aumento dos seus ganhos e, ao mesmo tempo, redução dos seus riscos de produção. Este fator se torna importante não somente no Cenário $1 \mathrm{c}$, mas para todos os demais cenários aplicados neste trabalho, pois, apesar de o objetivo do produtor aqui considerado consistir na maximização dos seus rendimentos, o risco é um fator determinante nas estratégias de produção. Porém, para resultados mais precisos, seria necessária a incorporação do fator risco ao modelo.

\section{CONCLUSÕES}

1. O modelo básico apresentado pelo estudo indicou a incapacidade de os sistemas de integração lavoura- 
-pecuária competirem, economicamente, com os sistemas tradicionais de cultivo, na região Centro-Norte do Estado do Mato Grosso, principalmente para a soja e o milho.

2. A partir da análise realizada, foi possível deduzir que as ferramentas implantadas pelo Plano ABC, visando a aumentar a área plantada com sistemas de integração lavoura-pecuária, são insuficientes. Mesmo proporcionando taxas de juros mais baixas, é, economicamente, mais atrativo para o produtor da região continuar cultivando soja e milho dentro dos sistemas tradicionais, em detrimento aos sistemas de ILP.

3. Os resultados apresentados pelo cenário estipulado indicaram que a implantação do sistema de CRE, para reduções advindas de mudança no uso da terra, pode ser um importante instrumento para o fomento da produção em sistemas de ILP, na região. Porém, esta eficiência dependerá dos valores de comercialização dos CRE. Aos valores de U\$ 2,00 e U\$ 15,00 por tonelada de $\mathrm{CO}_{2}$ equivalente não emitido, o produtor não alteraria a sua estratégia produtiva. Porém, ao valor de U\$ 25,00, o produtor ocuparia grande parte do seu estabelecimento com sistemas de ILP.

\section{REFERÊNCIAS}

CARVALHO, J. L. N. Dinâmica de carbono e fluxo de gases do efeito estufa em sistemas de integração lavourapecuária na Amazônia e no Cerrado. 2009. 143 f. Tese (Doutorado em Solos e Nutrição de Plantas) - Escola Superior de Agricultura Luiz de Queiroz, Universidade de São Paulo, Piracicaba, 2009.

DENT, J. B.; HARRISON, S. R.; WOODFORD, K. B. Farm planning with linear programming: concept and practice. London: Butterworths, 1986.

FIGUEIREDO, M. G. et al. Relação econômica dos setores agrícolas do Estado do Mato Grosso com os demais setores pertencentes tanto ao Estado quanto ao restante do Brasil. Revista de Economia e Sociologia Rural, Brasília, DF, v. 43, n. 3, p. 557-575, 2005.

FINCO, M. V. A.; BAUER, S. Bioenergy economics: an analysis of oil seed farming and biodiesel production in the Brazilian Savannah. Weikersheim: Margraf Publishers, 2010.

GONÇALVES, S. L.; FRANCHINI, J. C. Integração lavoura-pecuária. Londrina: Embrapa Soja, 2007. (Circular técnica, 44).
HAZELL, P. B. R.; NORTON, R. D. Mathematical programming for economic analysis in agriculture. New York: Macmillan, 1986.

HELMERS, G. A.; YAMOAH, C. F.; VARVEL, G. E. Separating the impacts of crop diversification and rotations on risk. Agronomy Journal, Madison, v. 93, n. 6, p. 13371340, 2001.

INSTITUTO BRASILEIRO DE GEOGRAFIA E ESTATÍSTICA (IBGE). Censo Agropecuário - 2006. Rio de Janeiro: IBGE, 2006.

INSTITUTO MATOGROSSENSE DE ECONOMIA AGROPECUÁRIA (IMEA). Boletim Agropecuário 2009. Cuiabá: IMEA, 2010.

INSTITUTO MATOGROSSENSE DE ECONOMIA AGROPECUÁRIA (IMEA). Boletim Agropecuário 2012. Cuiabá: IMEA, 2012.

INTERGOVERNAMENTAL PANEL ON CLIMATE CHANGE (IPCC). Climate change 2007: the physical science basis. Cambridge: Cambridge University Press, 2007.

KITCHEL, A. N.; COSTA, J. A. A.; ALMEIDA, R. G. Produtividade de forragem em sistemas de cultivo simultâneo de capins com sorgo forrageiro. In: REUNIÃO DA SOCIEDADE BRASILEIRA DE ZOOTECNIA, 46., 2009, Maringá. Anais... Maringá: UEM, 2009. 1 CD-ROM.

KLUTHKOUSKI, J. et al. Renovação de pastagem no Cerrado com arroz: sistema Barreirão. Santo Antônio de Goiás: Embrapa Arroz e Feijão, 1991.

MACHADO, L. A. Z.; BALBINO, L. C.; CECCON, G. Integração lavoura-pecuária-floresta: 1 . Estruturação dos sistemas de integração lavoura-pecuária. Dourados: Embrapa Agropecuária Oeste, 2011. (Documentos, 110).

MARTHA JÚNIOR, G. B; ALVES, E.; CONTINI, E. Dimensão econômica de sistemas de integração lavoura pecuária. Pesquisa Agropecuária Brasileira, Brasília, DF, v. 46, n. 10, p. 1117-1126, 2011.

OLIVEIRA, P. P. A. et al. Fertilização com N e S na recuperação de pastagens de Brachiaria brizantha cv. Marandu em Neossolo Quartzarênico. Revista Brasileira de Zootecnia, Viçosa, v. 34, n. 4, p. 1121-1129, 2005.

TOWNSEND, C. R.; COSTA, N. L.; PEREIRA, R. G. D. A. Aspectos econômicos da recuperação de pastagens no bioma Amazônia. Porto Velho: Embrapa, 2009. (Documentos, 131).

VILELA, L. et al. Integração lavoura pecuária. In: FALEIRO, F. G.; FARIAS NETO, A. L. Savanas: desafios e estratégias para o equilíbrio entre sociedade, agronegócio e recursos naturais. Planaltina, DF: Embrapa Cerrados, 2008. p. 933-962. 